\title{
Physical Maturity Assessment
}

National Cancer Institute

\section{Source}

National Cancer Institute. Physical Maturity Assessment. NCI Thesaurus. Code C89518.

A physical examination of a newborn's developmental characteristics. 